\title{
How Well-Protected are Teachers in School?
}

\author{
Alma Sonia Q. Sanchez-Danday \\ Leyte Normal University \\ Philippines
}

\begin{abstract}
School leaders are responsible in providing a socially just environment for teachers. However, studies revealed a low education law literacy of school heads to adequately protect teachers' rights. This study sought to describe how 10 purposively chosen faculty organization presidents from the different public higher education institutions (HEIs) in the Philippines handle cases involving teachers. The common issues and challenges encountered were likewise determined through a descriptive single case study design. Methodological triangulation was used in gathering the data thematically analyzed with the aid of NVivo qualitative data analysis software. Results revealed the different misconceptions of the members of the disciplinary committee, the preference of settlement over the resolution of cases, and the presumed existence of a conflict of interest among faculty presidents designated to a supervisory position. Recommendations for further actions were likewise given.
\end{abstract}

Keywords: teacher rights; settlement versus resolution; education law cases; teacher protection; higher education institutions.

\section{Introduction}

School leaders are in the immediate position of responsibility in providing social justice, equity, and protection of teachers' and students' rights in the academe.

Studies highlighted the moral responsibility of school leaders and administrators in protecting the rights of stakeholders in the educational organization (DiPaola \& Tschannen-Moran, 2001; Dunklee \& Shoop, 2002; Hernandez \& McKenzie, 2010; Theoharis, 2007). Hartmeister (1995) even enumerated the different rights and responsibilities of teachers to avoid violating constitutional and statutory rights in school. However, studies revealed an inadequate education law literacy of school heads (Brabrand, 2003; Eberwein, 2008; Militello, Schimmel, \& Eberwein, 2009) which could have helped in providing a socially just school community.

School leaders were then encouraged to equip themselves with the relevant education laws to address the changing demands of the society (Gordon, 1997, 
Militello, Schimmel \& Eberwein, 2009; Redfield, 2003; Taylor, 2001) and to address the gaps in the education law trainings of teachers (Brown, 2004; Corcoran, 2007; Schimmel \& Militello, 2007). Gullatt and Tollett (1997) even suggested making education law a requisite course to prepare the teachers before the field exposure. The study of Gajda (2008), however, found that states expect only a minimal competency of teachers in education law and is thus not addressed in the teacher licensure examinations.

Unfortunately, an increase in the number of litigations was observed against schools and teachers throughout the years (Eberwein, 2008; Russo, 2011; White, 2012) which may be attributed to the awakened legal consciousness of the society. Though education law is perceived to be of paramount importance in the academe, the study of Schimmel and Militello (2007) revealed that most teachers are uninformed or misinformed about their rights and would rather rely heavily on information provided by their colleagues. They also found that teachers have the desire to learn more about laws affecting them, yet they have not taken a course in education law. Fischer, Schimmel, and Stellman (2003) and McCarthy and Cambron-McCabe (1981) further explained that the legal issues involving the rights of teachers cover a wide range of areas from contracts, abuse, freedom of expression to academic freedom.

In the Philippines, several administrative, civil, and criminal cases involving teachers have been filed in courts and other quasi-judicial bodies. However, there is a dearth of literature, locally and internationally, exposing how well protected the teachers are in facing these problems and how knowledgeable they are of the issues confronting them.

As a practicing lawyer connected with the academe, the researcher has been exposed to several issues and problems faced by a public higher education institution (HEI) either as a counselor or adviser, grievance committee member or as a passive observer. The researcher humbly opines that most of the issues would not have surfaced if the school leaders who are charged with the daily responsibility of operating the schools within legal boundaries have a working knowledge of some education laws. Additionally, some issues could have been prevented if teachers have developed legal consciousness.

\subsection{Research Questions}

To shed light on the experiences of the people who are tasked to represent the teachers in school, the study sought to answer these questions:

1. What are the common issues faced by teachers in higher education institutions?

2. How do higher education institutions handle issues involving teachers?

3. What are the challenges faced by faculty organization presidents in case resolutions? 


\section{Theoretical Framework}

This study is anchored upon educational leadership theories such as the transformative leadership theory and the critical social theory. Educational leadership has been defined by Santamaria (2016) as the professional practice of leaders in guiding and influencing educators toward improving learning and in other educational processes.

A seminal study on leadership identified categories of leadership as either transactional or transformational (Burns, 1978) leading to what is known as transformative leadership which Shields (2010) believe to meet both the academic and social justice needs of the complex and diverse education systems with an end goal of achieving individual, organizational, and societal transformation. This study anticipates for teachers to realize their important role in achieving transformation within the educational organization.

Another theory considered for this study is the critical social theory (Leonardo, 2004) emphasizing the need for teachers to confront realities of social inequality with the hope of driving them to critically reflect about their experiences and to find out the strengths and weaknesses of the protocols they follow.

\section{Methodology}

The study utilized the descriptive single case study design as described by Baxter and Jack (2008). Ten faculty organization presidents for school year 20182019 from the 10 public higher education institutions in Region 8 of the Philippines were purposively chosen as the participants in the study assigned as Teacher 1 [T1] to Teacher 10 [T10]. Saturation of data (Glaser, Strauss, \& Strutzel, 1968) was considered in determining the sample size. The participants were chosen based on the following inclusion criteria: 1) their unique characteristic such as their exposure to legal issues of teachers in school; 2) willingness to participate in the interview and other follow-up interviews; 3) willingness to have the interviews audio-recorded; 4) willingness to show documents, records, and other evidence needed to substantiate answers; and 5) ability to communicate thoughts and to expound on their answers.

A methodological triangulation as described by Guion, Deihl, and McDonald (2011) was used in gathering the data and to test validity through the convergence of information from different sources (Carter, Bryant-Lukosius, DiCenso, Blythe, \& Neville, 2014). Multiple data collection methods were used generated from individual interviews, archival records, and documents. The content of the interview protocol included key research questions with probe questions to elicit exhaustively the participants' response. Interviews were audio-recorded and held in the place convenient to the participant with minimal interruption and privacy risks. Follow-up interviews were done personally, through electronic mail correspondence or phone calls at the participants' preference. Thematic analysis of data was done with the aid of NVivo qualitative data analysis software. 
As suggested by Cope (2014), the trustworthiness of the study was established through by verifying the findings with the faculty organization presidents involved, seeking interpretation concurrence with another researcher, providing rich quotes from the interview to support the interpretation, and by considering data saturation in conducting the interviews.

\subsection{Ethical Considerations}

Data gathering commenced after the issuance of an ethical clearance by an accredited research ethics committee in the region. Informed consent forms were also given to the participants to inform them of the study purpose, risks, and benefits. Transcripts of the interviews were shown to the participants for verification.

\section{Findings}

The participants were able to disclose the different issues faced in their respective institutions, the protocols in resolving the issues, and the challenges encountered in the process.

\subsection{Common Issues Facing Teachers in HEIs}

The participants revealed several issues confronting the teachers in the academe. These issues could further be classified into issues between the school and its teachers, issues between and among teachers, and issues between the teachers and their students.

\subsubsection{Issues between teachers and the school}

Some participants identified the existence of corruption as one of the main sources of legal issues. They asserted that there would have been sufficient provisions for the faculty members to improve their working conditions if the budget allotted for this purpose has been utilized properly. Manifestations of corruption, according to one participant, could be seen from the administration's act of misrepresenting and falsifying important documents presented to the Board of Regents.

One controversial issue which affects teachers' right to be promoted was the adoption of mixed criteria in the faculty merit system for promotion. The participant shared:

"We have 48 vacant items in *** since 2015 but because of the double criteria from the National Budget Circular (NBC) and the CSCapproved (Civil Service Commission) merit system adopted by our university, these items were not filled up yet. It affects the faculty members since they know that there is a vacancy, they know they are qualified, in fact, they applied for it because of the Special Order issued by the president, yet nothing happens. It demoralizes those who have been here for 10 to 20 years knowing that there is a mechanism for promotion which is not being implemented." [T7]

Some conflicts also arose from internal policies of the institution such as the no overload policy, no clearance-no salary policy, and the no research-no service 
credit policy which was opposed by the faculty members until it was recently modified in favor of the faculty. A participant expressed his sentiment below:

"The service credits we earned will not be credited unless there's a research. In other words, a research output was made as a precondition to receive service credits." [T4]

Other issues mentioned include internal differences and actions of the administration which affected the faculty members such as the problem on disallowances, collective negotiation agreements between the institution and its staff, and the recognition of the rightful bargaining representative. Some institutions have unrecognized and unregistered faculty unions and are paying a bargaining fee with the staff union which stands as the bargaining agent of the institution. Another issue involves the slashing of a certain amount from their monetary benefits for those not entitled to receive the bonus. The participant clarified, however, that the teachers were not against this act of generosity but of the manner by which deductions were made without their prior consent. There were also issues on violations of due process such as the giving of sanctions to teachers for tardiness without charge and the issues on the probationary period for the appointment of temporary to permanent teachers.

\subsubsection{Issues between colleagues}

With regard to teacher problems and issues with their colleagues, most participants revealed that though there were squabbles, the issues were trivial that teachers would not bother to file a formal complaint. Most of the conflicts between teachers arose from misunderstanding, miscommunication and insensitive pranks.

One issue mentioned was a serious administrative offense which involved the tampering of a public document or a Daily Time Record (DTR) by a participant's immediate supervisor. She shared:

"I accomplished a DTR for my overload then I submitted it to my immediate supervisor for her signature. I was surprised when I was called by the cashier's office questioning why there were a lot of corrections in my DTR. I confronted my head and she justified that she just crossed from my DTR the days in which, she believed, my services were not rendered." [T9]

\subsubsection{Issues between teachers and students}

Reported issues between teachers and students were mostly on harassment issues committed by teachers, violation of the no-collection policy, and on abuse of academic freedom in capriciously assigning grades and in giving assignments and projects. Though uncommon, there were also cases initiated by teachers against students. Participants disclosed about a teacher bullying incident and on the hacking of teachers' online accounts by students.

Another participant had an experience of settling a complaint by a teacher against an entire class for an alleged cheating act when he discovered that 
someone took a picture of his examination questionnaire and leaked it to his classmates through messenger.

"In that cheating incident, the guidance counselor suggested for the teacher to make another set of questions since he, too, was liable. The teacher, however, wanted to fail all the students in that class to serve as a lesson to these students." [T9]

This situation may seem ordinary but this accentuates both the right and responsibility of the teachers to maintain the privacy of their documents. This also justifies the need for teachers to update themselves with education laws to correct misconceptions such as the belief that a blanket penalty is applicable.

\subsection{Dealing with Teacher Issues in HEIs}

The procedure shared by the participants on complaints involving teachers all require, initially, the submission of a formal written complaint before taking any action. Subsequent hearings follow where parties involved are called separately and then jointly with the utmost goal of reaching a compromise or reconciliation. Protocols, nonetheless, vary. Others require that the issue will be brought to the faculty organization first for its resolution before it is elevated to a body which will be created for that purpose. Generally, the faculty organization presidents are asked to sit on the deliberations or investigations involving a faculty member. However, in some institutions, the participants were excluded from the special orders issued by the president to compose the disciplinary committee, hence, they were not able to represent the faculty.

The answers also revealed a variable composition in these created disciplinary committees. Constant of which are the immediate supervisor of the faculty concerned and a representative of students when it involves issues between teachers and students. In other institutions, the human resource management officer, guidance counselor, legal officer, and other disinterested senior faculty members are included. Other institutions opted to include only the administrators and teachers not connected with the concerned faculty for impartial determination of the cases. One participant, likewise, shared that the composition of the grievance or disciplinary committee is very clear in their university code. She is just not sure whether their president is oblivious or is purposively overlooking this fact in choosing the members of the ad hoc committee. Notably, all institutions have organized a Committee on Decorum and Investigation (CODI) for sexual harassment cases as mandated under CSC Resolution No. 01-0940.

\subsubsection{Settlement versus resolution of cases}

Very few of the cases were resolved with finality at the school level and appurtenant to this, teacher violators were seldom punished. A participant distinguished the difference between a CSC-initiated complaint versus a complaint which originated at the institution level as to the treatment of cases. He said: 
"In my 13 years of incumbency as a faculty organization president, all cases and issues were settled at the institution level. We have a very clean record. So far, no teacher has been sanctioned yet even if substantial proof exists. We largely depend on the decision of the complainant. Well, except the one dismissed by the CSC after finding the teacher guilty for dishonesty. But, it was a different matter altogether since the action originated from the CSC." [T1]

\subsubsection{Resolving cases based on merits and procedural technicalities}

Though grievance proceedings are not supposedly bound by legal rules and technicalities, some institutions' policy in lodging complaints follows certain technical rules. Other institutions pay close attention to the form of the complaint based on their protocol which they adopted from the Revised Rules on Administrative Cases in the Civil Service (RRACCS). They require the subscription of a notary public for the complaints filed as a requirement for validity. One participant admitted, though, that:

"We always tell the complainants that we will conduct interviews and investigations to determine probable cause, however, they need to have their complaints subscribed to be considered valid. Sadly, they would not pursue once they learn that they need to have the complaints notarized. Then, we send them a letter stating that failure to subscribe means we cannot go further with the investigation." [T6]

\subsection{Challenges in Issue and Case Resolutions}

Several challenges in resolving the teacher issues in higher education institutions could be gleaned from the participants' answers.

\subsubsection{Misconceptions on education law}

Several misconceptions were discovered which affected not only the substantive knowledge of the participants but also their apprehension of applicable laws and procedure. These misconceptions include the belief that the CODI cannot push through with a sexual harassment case once the complaint is withdrawn despite the existence of substantial evidence and the inaction on cases involving students and teachers outside the university for lack of jurisdiction. The lack of awareness of some teachers on the impact and gravity of offenses and the authority vested by law to the disciplinary committee in some cases was also revealed. They shared:

"Between students and teachers, we only have informal complaints. For example, a student would tell me about a teacher requiring them to photocopy exam papers. I have not encountered serious issues yet regarding teachers and students." [T8]

"I heard of students complaining against their teachers for sexual harassment after they have reported already to the dean and vicepresidents. I am apprised as the faculty president. I would tell them to put it in writing but it usually remains unheeded. The issue stops there. 
We can't just report it nor can we act on it if it's not in writing. That's the main reason why most cases do not prosper." [T6]

These answers expose the lack of substantive knowledge of some administrators on some applicable laws.

\subsubsection{Misinformation}

Some participants shared that they have faculty members who have distorted views about their rules and procedures. This information ranges from the assertion that no faculty manual means no basis to file a case to the belief that subscribing a complaint before a notary public presupposes an intention to place the person behind bars. Others involve misinformation of administrators with regard to the processes and the scope of their power and authority in imposing discipline. They shared:

"We have teachers whose confidence are misplaced. They keep on arguing that no case could be filed against them because we do not have a faculty manual yet." [T3]

"No matter how I explain to the teachers, some would be immediately held back once we require their complaint to be notarized. They would contend that they planned to inform the school about the misconduct only and not for the purpose of incarcerating anyone." [T6]

\subsubsection{Presumption on the Existence of Conflict of Interest}

One administrator-participant gave very positive feedback about their institution and their teachers and shared that in his experience as a faculty organization president for three years, he encountered only a very minor issue which was about according a permanent appointment to a teacher. He shared:

"We are quite peaceful. It's because we have the best president so farthat's due to the fact that our president is a woman. We don't have problems encountered even if you ask around. If there were, they were already resolved at the college level so though we have a disciplinary committee in our constitution and by-laws, it's not being utilized." [T5]

Resembling answers were given by most of the faculty organization presidents who, at the same time, are holding supervisory functions or administrative positions in the institution.

\subsubsection{Administrative interventions}

Another challenge identified are the interventions done by the administration in the investigation process with the goal of unduly influencing its outcome. An example of this is the bypassing of some protocols and the exclusion of the faculty organization presidents from the composition of the committee on discipline which is otherwise specified in their university code or manual. Institutions with bigger student and teacher populace usually have grievance machinery lodged at their respective colleges and through their union. A participant revealed, however, that most teachers would opt to file their complaints with the union because of partisanship. He said: 
"Most faculty members would not go to the grievance machinery of the college because of partisanship. The union would, instead, resolve their interpersonal grievances." [T7]

Some participants also shared that the administration's act of intervening with their investigation, bypassing their authority, and ignoring recommendations often led to the non-imposition of sanctions, violation of due process, arbitrary decisions, and repetition of adverse actions.

\subsubsection{Inner Struggles and Cultural Influences}

The answers of some participants also revealed the presence of inner struggles of those tasked to investigate and resolve the issue. This often leads to procrastination instead of taking immediate actions to resolve the complaint. One participant shared that in their protocol, conflict resolution should start with the Unit, Department Head, and the Dean before it reaches the grievance committee which conducts observations and gives recommendations to the president, then from the latter to the Board of Regents. Notwithstanding this protocol, the participant added:

"It usually goes straight to the grievance committee instead of being treated at the department level first. In our department, no issue has been resolved even at the Unit level. It is because we are all friends there (laughs). We don't like to hurt or to trespass on the rights of others. So even if students have grievances with a particular teacher, it is not settled at the department level." [T2]

This snippet reflects a situation where the people charged with the function of investigating the issues are personally conflicted to do so, thus, the need for disinterested persons to apprehend facts properly and give reasonable recommendations.

Another factor which affects the turn-out of the proceedings is the Filipino culture of mercy which makes complainants hesitant in formally filing a case or which makes them withdraw the complaint once filed. The participant disclosed:

"I asked the teacher why she withdrew her complaint against a colleague. She replied that the penalty may cause her colleague to be dismissed from government service and she does not want to be guilty of inducing them to poverty." [T10]

\section{Discussion}

It could be gleaned from the answers that some issues between the school administrators and the teachers arise because of inadequate education law literacy of administrators which support the findings of Brabrand (2003), Eberwein (2008), and Militello, Schimmel, and Eberwein (2009).

In one institution, the faculty promotion issues could have been precluded if the administrators were well-informed that the provisions of the institution-based 
faculty merit system should not go beyond that of the NBC 461-merit system. In the Philippines, the promotion of teachers in public higher education institutions is well-defined under NBC 461 issued on June 1, 1998 by the Department of Budget and Management to thwart promotion based on personal considerations by the head of the institution through the provision of an objective points-based system to reach a particular rank (Veloso, 2014).

Notably, the answers also show that a different approach is imposed once the conflict is between the teachers and their superiors. Participants shared about the tendency of some school administrators to abuse their authority and the relaxation of school rules once school heads are involved. The dissatisfaction of teachers in the resolution of conflicts between the teachers and their heads conform to the findings of Makaye and Ndofirepi (2012) as to the process of resolution and the cause of conflict which is primarily about unequal resource allocation.

The bullying incidents to teachers by the students are quite alarming. These suggest an increasing student confidence to commit infractions of law because of the multiple avenues available to them. These students, too, have the misconception that they are unreachable because of anonymous social accounts. Schools should then aim to have education law literate administrators, staff, teachers, and students.

The answers of the participants as to how they deal with legal issues in school show an apparent confusion between the concepts of administrative offenses and grievable matters. Grievable matters are subject to the discretionary power of the president or the Board of Regents while administrative offenses are not. Administrative offenses which include serious infractions like falsification and tampering of public documents should have been lodged with the administrative council or with the proper government offices. Matters subject to the grievance machinery of the school include, among others, work-related issues and inequitable application of school rules or policies. It has been observed, however, that most grievance committees treat complaints falling under the first category. Ironically, as practiced, these committees "settle" and "resolve" even the commission of administrative offenses. Examples of these administrative offenses which were treated under the grievance committee were falsification and tampering of public documents which are supposed to be nongrievable matters.

Likewise, the answers pointed to the fact that the participants' experiences in dealing with disputes, conflicts, and even legal issues in schools mostly revolve around the settlement level without addressing the sources of the issues. In a litigation context, settlement means that all elements are in place to end a conflict without addressing its root cause while resolution requires the unearthing of what has caused the conflict and then dealing with it (Deihl, 2010). Though it seems on the surface that the problems were forestalled, relationships still had a tail of lingering bad feelings. 
The practice, too, of some institutions in following legal rules and technicalities in case resolution gives rise to arguments of placing more weight on technicalities over the merits of the complaints. Strict and rigid technicalities are usually required in court-lodged cases and not on school-received complaints.

Several drawbacks in the proceedings were also noted. Some participants disclosed the absence of a joint hearing and the limited number of hearings called for by the disciplinary committee before the issuance of its resolution, the issuance of a decision with no justification or explanation to enlighten the complainant, inactions on cases referred back by the CSC to investigate and retracted cases on alleged administrative offenses with substantial evidence, and the resort to use blackmail to force complainant to settle alleging that pursuing the case will tarnish the name of the institution which complainant is bound to protect. These flaws confirm the findings of Militello, Schimmel, and Eberwein (2009), Redfield (2003), and Theoharis (2007) that school leaders are ill-equipped with necessary know-how to act on their moral responsibility to protect teachers' rights.

The participants' answers, likewise, disclosed misconception of education laws as one challenge in resolving cases. Misapprehension of applicable these laws, especially those incorporated already in the school policies, may affect discernment in case resolutions. This error will have a multiplier effect to violations of rights if not properly rectified. In the same manner, having faculty organization presidents designated to supervisory functions may imply the existence of a conflict of interest or opposing loyalties that could deter a better representation of teacher cases or issues. Though not necessarily prohibited by some organizations, this situation needs to be managed properly for its potential to undermine a person's impartiality.

\section{Research Restrictions}

Since the study is limited only to the 10 public higher education institutions in the Eastern Visayas Region (Region 8) of the Philippines, the scope of the study may be expanded to other institutions outside the region to give a holistic view of the protocols and challenges in the resolution of teacher issues.

\section{Implications and Recommendations}

School initiatives and interventions in the area of education law are found wanting. Findings imply the need to re-visit and re-orient the members of the grievance and disciplinary committees handling teacher issues on the definition of administrative offenses and grievable matters and the scope of the disciplinary committees' jurisdiction. The teachers, as well as their representatives involved in the settlement of legal issues and conflicts, may need to be re-trained on the substance of applicable laws to avoid improper apprehension of facts and procedural lapses. To do so, an appropriate education law program for teachers and administrators may be initiated by the school and its faculty organization. 
The giving of supervisory functions to faculty organization presidents in higher education institutions may incite conflict of interest in favor of the administration in cases between the latter and the teachers. This may lead to organizational chaos in the long run. Hence, the administration and the faculty president involved may need to consider this possibility before exercising their discretion. A policy prohibiting this situation may even be better for the institution.

The practice of settling cases instead of resolving them may be used as an administrative mechanism to thwart justice, especially when the subject matter pertains to administrative offenses, and to prevent the reputation of the school from being dragged in litigations at the expense of truth. The school policy of requiring certain rules and technicalities to be followed in lodging complaints may also be used as a mechanism to impliedly rid the disciplinary office and the institution, in general, from warranted and unwarranted claims. The institutions having this practice may need to reconsider this policy to promote justice.

Further studies may focus on the development of materials and appropriate intervention schemes to help the faculty organization presidents and members of disciplinary committees in the area of education law.

\section{References}

Baxter, P., \& Jack, S. (2008). Qualitative Case Study Methodology: Study Design and Implementation for Novice Researchers. The Qualitative Report, 13(4), 544-556.

Brabrand, S.S. (2003). Virginia principals and school law. Virginia Polytechnic Institute and State University. Pro Quest Dissertations \& Theses.

Brown, Q. L. (2004). An inquiry into secondary teachers' knowledge of school law in one rural southwest Georgia county. Pro Quest Dissertation and Theses.

Burns, J. M. (1978). Leadership. New York: Harper \& Row.

Carter, N., Bryant-Lukosius, D., DiCenso, A., Blythe, J., \& Neville, A. J. (2014). The Use of Triangulation in Qualitative Research. Oncology Nursing Forum, 41(5), 545-547. doi:10.1188/14.onf.545-547

Cope, D. G. (2014). Methods and Meanings: Credibility and Trustworthiness of Qualitative Research. Oncology Nursing Forum, 41(1), 89-91. doi:10.1188/14.onf.89-91

Corcoran, T. (2007). The changing and chaotic world of teacher policy. In D. Cohen, S. Fuhrman, \& F. Mosher (Eds.). The State of Education Policy Research, 307-335. London: Lawrence Erlbaum Associates Publishers.

Diehl, S. M. (2010). The Difference Between Settlement and Resolution. Retrieved from: http://www.adrhub.com/profiles/blogs/the-difference-between

DiPaola, M. \& Tschannen-Moran, M. (2001). Report on the 2001 Principals Study. Williamsburg: The College of William and Mary.

Dunklee, D. R. \& Shoop, R. J. (2002). The Principal's Quick-Reference Guide to School Law: Reducing Liability, Litigation, and Other Potential Legal Tangles. Thousand Oaks: Corwin Press.

Eberwein, H. J. (2008). Raising legal literacy in public schools, a call for principal leadership: A national study of secondary school principals' knowledge of public school law. Pro Quest Dissertations \& Theses.

Fischer, L., Schimmel, D., \& Stellman, L. (2003). Teachers and the law. Allyn \& Bacon/Longman Publishing. 
Gajda, R. (2008). States' expectations for teachers' knowledge about school law. Action in Teacher Education, 30(2), 15-24. doi: 10.1080/01626620.2008.10463488

Glaser, B. G., Strauss, A. L., \& Strutzel, E. (1968). The Discovery of Grounded Theory; Strategies for Qualitative Research. Nursing Research, 17(4), 364 doi:10.1097/00006199-196807000-00014

Gordon, H. R. D. (1997). Legal knowledge of secondary school principals: Impact of selected variables. Paper presented at the Annual Eastern Educational Research Association Conference (20th, Hilton Head, SC, February 19-22, 1997).

Guion, L. A., Diehl, D. C., \& McDonald, D. (2011). Triangulation: Establishing the validity of qualitative studies (FCS6014). Retrieved from http://edis. ifas. ufl. edu/pdffiles/FY/FY39400. pdf

Gullatt, D. E., \& Tollett, J. R. (1997). Educational Law: A Requisite Course for Preservice and Inservice Teacher Education Programs. Journal of Teacher Education, 48(2), 129-135. doi:10.1177/0022487197048002006

Hartmeister, F. (1995). Surviving as a Teacher: The Legal Dimension. Precept Press, 160 E. Illinois Street, Chicago, IL 60611.

Hernandez, F., \& McKenzie, K. B. (2010). Resisting Social Justice in Leadership Preparation Programs: Mechanisms that Subvert. Journal of Research on Leadership Education, 5(3), 48-72. doi:10.1177/194277511000500302

Leonardo, Z. (2004). Critical Social Theory and Transformative Knowledge: The Functions of Criticism in Quality Education. Educational Researcher, 33(6), 11-18. doi:10.3102/0013189x033006011

Makaye, J., \& Ndofirepi, A. P. (2012). Conflict resolution between heads and teachers: the case of 4 schools in Masvingo Zimbabwe. Greener Journal of Educational Research, 2(4), p105-110.

McCarthy, M. M., \& Cambron-McCabe, N. H. (1981). Public school law: Teachers' and students' rights. Boston: Allyn and Bacon, pp. 336.

Militello, M., Schimmel, D., \& Eberwein, H. J. (2009). If They Knew, They Would Change. NASSP Bulletin, 93(1), 27-52. doi:10.1177/0192636509332691

Redfield, S. E. (2003). The convergence of education and the law: A new class of educators and lawyers. Indiana Law Review, 36, 609.

Russo, C. J. (2011). The yearbook of educational law 2011. Dayton, Ohio: Education Law Association.

Santamaria, L. M. J. (2016). Theories of Educational Leadership. Oxford Bibliographies Online Datasets. doi:10.1093/obo/9780199756810-0153

Schimmel, D. \& Militello, M. (2007). Legal literacy for teachers: A neglected responsibility. Harvard Educational Review, 77(3), 257-284. doi:10.17763/haer.77.3.842n787555138746

Shields, C. M. (2010). Leadership: Transformative. International Encyclopedia of Education, 26-33. doi:10.1016/b978-0-08-044894-7.00441-3

Taylor, K. R. (2001). What about legal literacy? Principal Leadership, 2(2), 66-70.

Theoharis, G. (2007). Social justice educational leaders and resistance: Toward a theory of social justice. Educational Administration Quarterly, 43 (2), 221-258. doi:10.1177/0013161x06293717

Veloso, A. J. (2014). Towards enhancing the merit systems in public higher education: A research on the development of a career system for state universities and colleges. Commission on Higher Education. Retrieved from https://www.academia.edu/24657471/Towards_Enhancing_the_Merit_System s_in_Public_Higher_Education_A_Research_on_the_Development_of_a_Career _System_for_State_Universities_and_Colleges

White, D. B. (2012). An assessment of the level of school law knowledge of South Carolina school principals and the implications for litigation and social justice (Doctoral dissertation, University of South Carolina). 